\title{
Misaligned Priorities: How Disconnect between Donors and Citizens Doomed AIDS Intervention in Africa
}

Even the group that is looking after sick people in this village do not really know everyone who has HIV ... I feel it is important that the village headman and other people should know because say if you want to marry someone, you have an idea of what is going on with them. If you get sick, other people will have an idea of how to address your sickness.

Headman Interview \#155, Balaka District, August 27, 2009

He repeated his question, “Why won't you list the names of everyone who tests positive?" He went on, suggesting the list could be kept by a respected elder in the village who would advise others on how to avoid infection. Glory, my Tanzanian teaching partner, retranslated the question, trying even simpler English words the second time to convey what the mzee (elder) at this community meeting in a rural village in Arumeru District was asking. But I understood his question perfectly the first time he asked it. My silence was not because I did not understand the question. My silence was a manifestation of my not understanding how we had failed to convince the most powerful people in this community of the importance of confidentiality in human immunodeficiency virus (HIV) testing.

After completing my first year in graduate school in 2004, I volunteered with a small nongovernmental organization (NGO) that coordinated partnerships between American university students and recent graduates of Tanzanian secondary schools to provide HIV awareness education in schools, and at large community gatherings. The village meeting where this mzee asked his question was a culmination of our efforts in the area following weeks of working in the local schools teaching HIV epidemiology and the current best practices for avoiding HIV infection. Previous volunteers were positive about these village meetings, characterizing them as celebrations marked with community acceptance of the knowledge imparted by well-trained volunteers. Of course, it is easy today to see the warts of this NGO's approach 
to HIV/acquired immunodeficiency syndrome (AIDS) intervention and the naïvete of its volunteers, myself included.

The mzee's question that day has stayed with me. For a long time, I regarded it as a failure: we had failed to change the minds of men and women in Arumeru to match our own ideas about how to respond to AIDS. Only after much learning and thinking did I take a new lesson from his question. In asking that the HIV status of villagers be publicized, he was offering a public health solution that could prevent the spread of HIV. This chapter's epigraph captures a similar sentiment from a village headman in Malawi. Our rejection of the mzee's proposal in Arumeru, Tanzania, in 2004 is consistent with many AIDS interventions I have witnessed and studied over the last decade: interventions are often funded and designed from afar and rarely engage influential people at the grassroots in shaping the nature of the intervention. In short, the people navigating the AIDS epidemic are objects to whom interventions are targeted. What this mzee was trying to demonstrate to me was that people navigating the AIDS epidemic also had ideas for intervention design. More simply, they had opinions on AIDS interventions.

AIDS has hit hardest in the young democracies of East and Southern Africa and a significant chunk of the funding for AIDS interventions is spent there. Yet these interventions do not reflect the opinions or ideas of their "intended beneficiaries." As this book will show, citizens and key decision-makers in the global community diverge on how AIDS interventions should be prioritized vis-à-vis other pressing policy issues. The significant threat AIDS poses to public health requires a strong response. However, failing to consider the ideas and opinions of African citizens in AIDS response could also take its toll. By privileging donor priorities over citizen priorities, global elites cripple states' abilities to implement policies representing citizens' interests. It is no small irony that the West has called for democratization in Africa while at the same time failing to recognize its interventions - like those against AIDS - undermine the fundamental democratic principles of citizen participation and representation.

Readers should not see this book as a pessimistic, misanthropic take on AIDS response in Africa. Rather, looking at our failures to improve the human condition can help us formulate better strategies and approaches going forward. Whether one's goal is fighting AIDS in Africa or poverty in your neighborhood, we must ask what the 
failures were in previous attempts. As my experience with the mzee in 2004 should show and as this book will argue, we must also ask and listen to the opinions and priorities of the ordinary people to whom interventions are targeted.

AIDS is one of the leading causes of death in the world and is the top cause of death in Africa. ${ }^{1}$ In 2016, UNAIDS estimated 1 million people died of AIDS. ${ }^{2}$ In the same year, another 1.9 million people were newly infected with HIV. There are 36.7 million people with HIV in the world and more than two-thirds of them live in Africa. Only 54\% of AIDS patients in Africa needing treatment have access to it. ${ }^{3}$

Billions of dollars have been spent to curb the AIDS epidemic. Donor governments spent $\$ 8.6$ billion in 2014 alone on anti-AIDS initiatives (Kates, Wexler and Lief, 2015). While this outpouring has had a tremendous impact - particularly in increasing treatment access in resource-poor countries - many donor-supported AIDS interventions have shown little objective impact on stemming the spread of HIV and bettering the lives of those affected by AIDS. For example, between 1997 and 2006, only $18 \%$ of projects in the World Bank's African Multicountry AIDS Program had satisfactory outcomes according to internal evaluations (Independent Evaluation Group, 2009, 38). When a mobilized international community commits billions of dollars to fight a disease, what impedes its efforts to improve outcomes for intended beneficiaries?

In this book, I identify obstacles in AIDS interventions. Scholars, journalists, and activists have pointed to insufficient political will and financial resources. ${ }^{4}$ But there is little variation in governments'

${ }^{1}$ HIV/AIDS was the cause of $11.7 \%$ of deaths in Africa in 2013; the next highest cause of death was lower respiratory infection, which accounted for $9.1 \%$ of deaths (Institute for Health Metrics and Evaluation, 2015).

2 Statistics come from AIDSinfo, a data portal managed by UNAIDS at http://aidsinfo.unaids.org (UNAIDS, 2017).

3 Author's calculations are based on UNAIDS data. It is important to note the significant variation across African countries. While $80 \%$ of HIV-positive Rwandans are reported to be accessing treatment, only $30 \%$ of HIV-positive Nigerians are on treatment.

${ }^{4}$ On the lack of political will, see Campbell (2003) and de Waal (2006). See Attaran and Sachs (2001) and Stover et al. (2002) for calls for greater financial resources. 
"political will" to fight AIDS and the global response to AIDS is one of the most heavily financed interventions to improve the human condition. Surely, political will and resource constraints are insufficient explanations for why many AIDS interventions have so little impact on improving the lives of their intended beneficiaries. I argue the critical characteristic challenging the global intervention against AIDS is its reliance on many actors to deliver the response.

More specifically, I argue the global intervention against AIDS in Africa has faced two related challenges. First, the global intervention's many actors complicate response. Decision-makers in corridors of power design interventions and then delegate responsibilities to faraway agents who ultimately shape the intensity and efficacy of response. These global interventions require coordination of multiple actors, not just across borders, but also across levels of governance within target countries. I show that delegating implementation across multiple levels of governance is ineffective, and in the worst-case scenarios creates opportunities for corruption.

Second, the many actors involved in the global AIDS intervention from international organizations making record financial commitments for fighting AIDS to the ordinary people themselves navigating AIDS in Africa - have misaligned priorities. One might expect that because AIDS is so devastating, there would be a global alignment of preferences: everyone wants good public health and AIDS is a serious threat locally and globally to public health. However, using public opinion survey data I join a growing chorus of scholars who show that Africans do not prioritize HIV/AIDS intervention, even in the world's worst affected countries. Unlike Western donors who highly prioritize AIDS interventions in Africa, citizens in African countries view AIDS as one of many problems they face and give it relatively less priority.

Misaligned priorities across the global supply chain of AIDS intervention make space for resources to be used in ways they weren't intended. For example, elites near the top of the global hierarchy can mismanage funds with little concern that their stewardship is being monitored by intended beneficiaries because citizens are focusing on other pressing issues. Likewise, agents implementing AIDS interventions may reappropriate or redirect resources toward issues more salient to themselves and more salient to the interventions' intended beneficiaries. In both of these scenarios, we would expect the 
resources intended for HIV/AIDS programming not having any impact on stemming the tide of the epidemic.

This book examines the disconnect between actors in the global intervention against AIDS in Africa. It focuses on how agents implementing interventions are pulled in different directions by two competing principals: the external donors funding interventions and the ordinary citizens who are the "intended beneficiaries" from whom local agents derive their legitimacy. When these two important constituencies have misaligned priorities, whose policy preferences will prevail? In a field mostly concerned with national-level policymaking, my research expands earlier scholarship on HIV/AIDS policy intervention by shifting perspective from international agency headquarters or state houses in African capitals to villages and peri-urban trading centers where agents are actually implementing programs at the grassroots.

While this is a book about AIDS in Africa, it is at the same time a book highlighting the challenges faced by health and development interventions in poor countries more broadly. The framework used here could be applied, for example, to interventions against famine. Like famine, AIDS is often seen as a problem particularly endemic to Africa and triggers a "humanitarian" response from the global community that then involves multiple countries and multiple levels of government to assess needs, deliver aid, and measure impact. Often the local reality of a humanitarian intervention is disjointed from how it was imagined in global corridors of power. Likewise, there is often a disconnect between the aid given and the needs and desires of intended beneficiaries. Like with AIDS, critical examination of famine interventions is met with counterfactual critiques that doing something is surely better than doing nothing. Without critical study of global interventions and thoughtful analysis of the local realities of these interventions, we will continue to recycle ineffective policy. I argue in the book's conclusion that interventions that proceed despite misaligned priorities can have negative consequences in young democracies like those facing serious AIDS epidemics. One contribution this book makes is to join the growing body of scholarly literature examining failures to improve the human condition in Africa (de Waal, 1997; Campbell, 2003; Autesserre, 2010). Like these earlier works, this book studies closely an intervention seemingly rooted in a humanitarian purpose and in which there are multiple actors and levels of actors involved. 


\subsection{Global Hierarchy, Grassroots Opinions}

Organizational charts of agencies and organizations involved in AIDS interventions are crowded and complicated with many actors and relationships between actors. Take for example the two graphics published in a UNAIDS document featured in Figure 1.1. These depictions of key organizations fighting AIDS in Tanzania and Mozambique seem like caricatures of the entangled web of "stakeholders" in AIDS intervention in Africa. The graphics make clear how complicated AIDS response is in two heavily affected countries. And yet, Figure 1.1 is missing at least one set of critical actors, namely, the people to whom interventions are targeted.

In Chapter 3, I present a stylized hierarchy of the many actors involved in AIDS response, from international donors to national governments and AIDS commissions to subnational middlemen and ultimately local agents and beneficiaries who, respectively, implement and receive AIDS interventions. Identifying the multiple levels of governance that are essential to AIDS interventions is an exercise in linking interventions as they are conceived in corridors of power to how they are ultimately implemented and received in African contexts.

International NGOs and national governments are essential to AIDS interventions in Africa because they furnish necessary resources; however, the provision and distribution of public health services must be done at the local level, thus the importance of local actors in implementation. One illustrative example is how the Malawian government rations care for AIDS patients. The Malawian government - as advised by the World Health Organization (WHO) and the Global Fund created an AIDS drug distribution policy in 2005 that limited access to AIDS drugs to Malawians with advanced disease (Ministry of Health [Malawi], 2005). The Malawian government receives funding for its national antiretroviral (ARV) treatment program from a few donors, predominantly the U.S. President's Emergency Plan for AIDS Relief (PEPFAR). In addition to relying on external donors for financial support, the Malawian government would also rely on local clinicians to determine patient eligibility on the basis of clinical presentation. ${ }^{5}$

\footnotetext{
5 When the aforementioned Malawian ARV policy was implemented, WHO guidelines recommended drug access for HIV-positive patients clinically presenting with symptoms of AIDS or HIV-positive patients with CD4 cell counts below $350 / \mu \mathrm{L}$ (World Health Organization, 2009, 10). Access to
} 


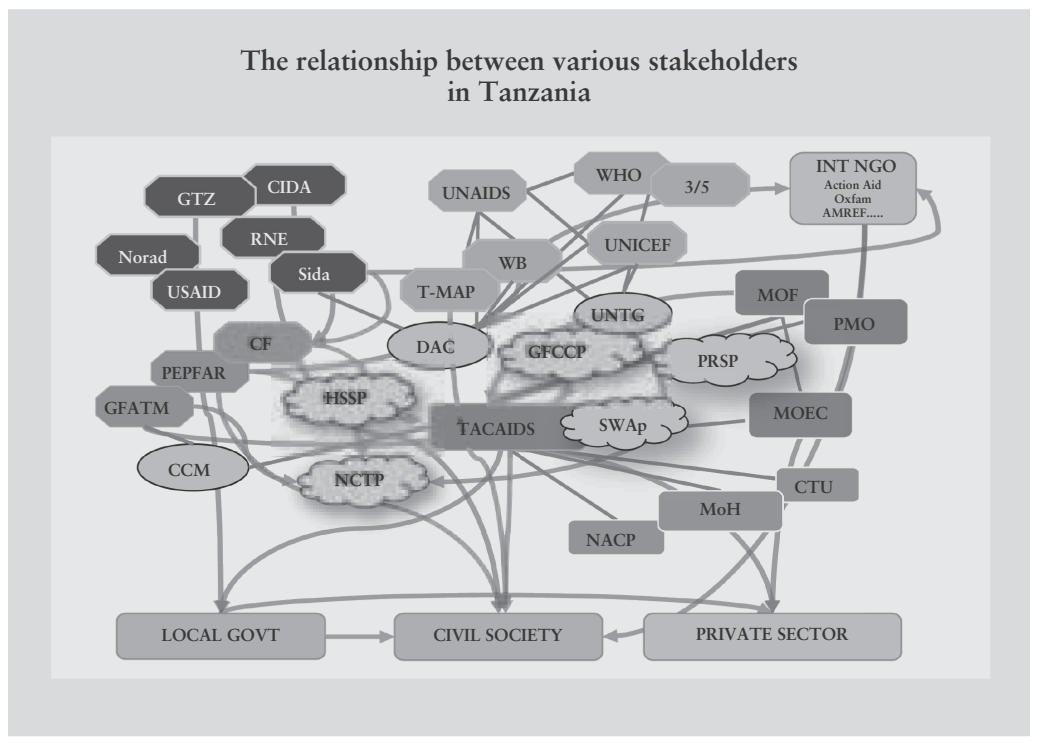

(a)

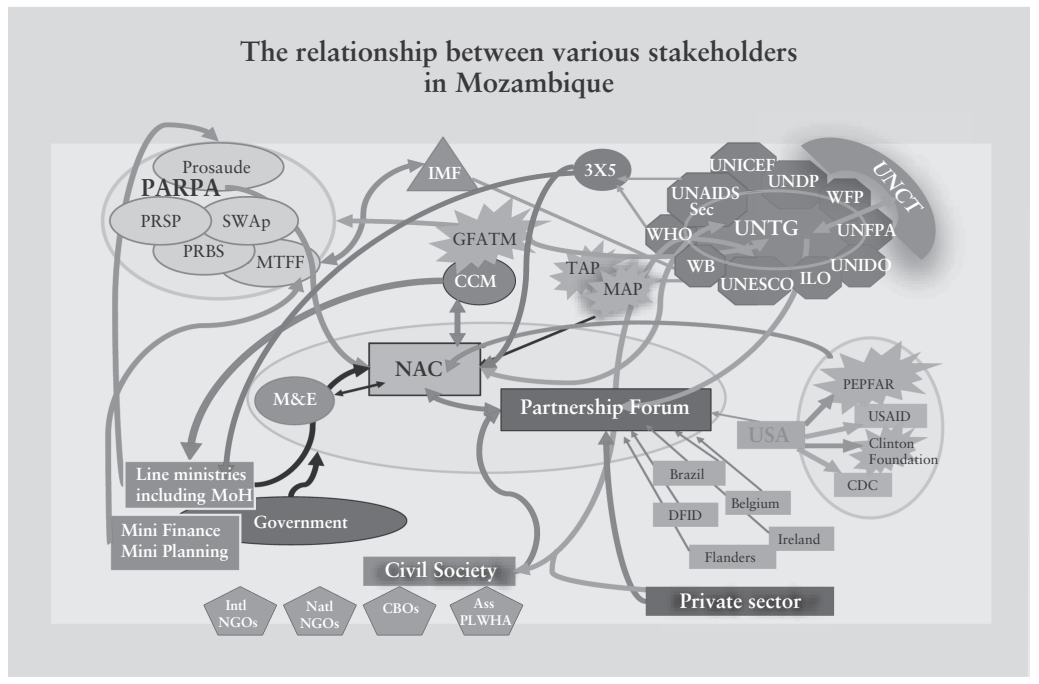

(b)

Figure 1.1 HIV/AIDS intervention stakeholders in Tanzania and Mozambique (a) Tanzania stakeholders, Figure 1 in UNAIDS (2005, 19) (b) Mozambique stakeholders, Figure 2 in UNAIDS $(2005,20)$ 
In this example, the principals of intervention are the Malawian government, the WHO, the Global Fund, and PEPFAR; the agents implementing the intervention were the Malawian clinicians, tasked with determining who among their friends, relatives, and community neighbors would obtain the limited access to life-lengthening therapy.

This simple example shows the intervention's success relies on the actions taken by multiple actors, but especially those of PEPFAR, the Malawian government, clinicians, and ultimately, patients. The intervention would end if PEPFAR discontinued financial support. The intervention would serve fewer AIDS patients if employees of Malawi's Ministry of Health or Ministry of Finance misappropriate PEPFAR funds meant for ARV provision. If doctors did not show up for work, there would be no one to diagnose and treat patients. If patients default on their treatment, their condition could worsen, which increases the likelihood they will infect someone else and that their HIV will mutate to be drug-resistant. The major takeaway here is that intervention success depends on each link in the global hierarchy.

Much of the scholarship on HIV/AIDS politics and policy typically employs a top-down framework examining the roles and response of national and international actors intervening against AIDS (Patterson, 2006; Bor, 2007; Lieberman, 2007, 2009; Dionne, 2011; Robinson, 2017). This book offers instead a bottom-up perspective. The provision and distribution of public health services must inherently be done at the local level, which requires we study the constraints and motivations of the agents actually implementing interventions. Local agents are integral to health and development interventions because of their proximity to and influence over intended beneficiaries.

Scholarship examining local agents in international aid interventions often focuses on motivating agents to be engaged and effective by better monitoring agents (Björkman and Svensson, 2009) or through monetary incentives (Banerjee, Duflo and Glennerster, 2008; Muralidharan and Sundararaman, 2011; Duflo, Hanna and Ryan, 2012). However, a growing literature studying health workers in Africa shows financial incentives are insufficient in motivating them and this literature underscores the value of other motivating factors (Franco, Bennett and

technology necessary to count CD4 cells has improved in Malawi in recent years; however, most HIV-positive Malawians relied on clinical diagnoses to access ARVs because of the limited availability or nonoperation of laboratory equipment capable of counting CD4 cells. 
Kanfer, 2002; Manongi, Marchant and Bygbjerg, 2006; Mathauer and Imhoff, 2006). My research suggests we should also consider nonmonetary motivations - such as agent policy preferences - and how those may constrain agent behavior. I argue that the disconnect we see between globally imagined HIV/AIDS interventions and the programs ultimately implemented is due to local agents actually implementing interventions on the ground acting in ways congruent with both their policy priorities and the policy priorities of ordinary citizens.

I focus on local implementation of HIV/AIDS interventions and citizens' prioritization of AIDS to address a set of general questions with implications for a wide range of foreign aid activities: do those who intervene against AIDS and the intended beneficiaries of AIDS interventions share common goals? Do they also have other, perhaps divergent, interests that they are simultaneously trying to maximize? If so, what are these interests, to what extent do actors diverge in prioritizing these interests, and will divergence lead to variation in the provision of interventions?

\subsection{Data and Methods}

To answer these questions, we must ask the opinions of agents implementing AIDS interventions in Africa as well as the opinions of the interventions' intended beneficiaries. Only recently through Afrobarometer - a Pan-African research network conducting public attitudes surveys in more than 30 African countries - have ordinary Africans been regularly polled about their opinions on politics and policies (Bratton, Mattes and Gyimah-Boadi, 2005). In young democracies in Southern Africa where AIDS is taking its toll, how aligned is AIDS response to citizens' priorities?

The data I marshal in this study were collected using a mixedmethods approach and include both original and secondary data sources. The original data draw entirely from fieldwork conducted in Malawi between 2006 and 2010 and includes survey interviews conducted with a random sample of rural Malawians, structured and open-ended interviews with village headmen and other key informants, archives of articles published on HIV/AIDS between 1998 and 2009 in Malawi's two major daily newspapers, and semi-ethnographic methods, like my field notes and diaries written by research assistants and a village headman living in a context of high HIV prevalence. I describe in more detail the data and methods used in this book in Chapter 4. 
I complement the Malawi data with secondary data from the broader context of HIV-affected countries in Africa. The secondary data I analyze include time-series cross-sectional survey data collected by Afrobarometer and the Demographic and Health Surveys in more than 30 African countries. I also use data compiled by international agencies like UNAIDS, the World Bank, and the Organisation for Economic Co-operation and Development (OECD) for HIV/AIDS indicators, development measures, and flows of official development assistance (ODA). Beyond the quantitative data, I draw on news articles and policy documents written by government agencies, major donors, and influential international organizations. The scope of my analysis is also broadened by a review of scholarly literature on HIV/AIDS, including peer-reviewed articles documenting biomedical advances, operations research studying effectiveness of interventions, and social scientific analysis of how people and governments are responding to the ongoing AIDS epidemic in Africa.

\subsection{Outline of the Book}

The net product of the chapters that follow is a framework for understanding challenges inherent to global interventions to improve health and development in Africa.

Chapter 2 is an overview and introduction to the AIDS epidemic in Africa and the corresponding response. It brings readers up to speed on the current state of the epidemic in Africa and details grassroots, national, and global responses to AIDS in Africa. In it I share examples of how AIDS interventions implemented at the grassroots level are disconnected from how they were imagined in global capitals. I also draw on scholarship about HIV exceptionalism to develop the book's argument.

In Chapter 3, I detail my argument about two related challenges facing AIDS interventions in Africa: principal-agent problems and misaligned priorities. First, I give an overview of the principal-agent problem, or the act where a person or group, known as a principal, relies on another person or group, known as the agent, to perform a task on behalf of the principal and be accountable to the principal in carrying out the task. I use the principal-agent framework to name the principals and agents involved in AIDS interventions in Africa and illustrate the pitfalls associated with delegating responsibility across a global supply chain of intervention through the example of a Kenyan 
corruption scandal. I also show in Chapter 3 that if we consider the policy priorities of agents as motivation for implementing interventions, we should expect divergence from international protocols at the grassroots level because of a global misalignment of priorities.

Chapter 4 zeroes in on Malawi, describing the political and epidemiological context, the response to AIDS, and the original data collected and analyzed in this book. Malawi is an excellent place to study AIDS because it, unfortunately, is one of the countries hardest hit by the epidemic. Malawi has the ninth highest HIV prevalence in the world, estimated at $9.2 \%$ of adults in 2016 (UNAIDS, 2017). Malawi's high HIV prevalence has captured the attention of donors, who wield significant influence in shaping AIDS response in Malawi, especially when compared to the power of ordinary citizens.

In Chapter 5, I substantiate the misalignment of AIDS priorities across levels of intervention - the empirical reality upon which the book's argument depends. First, I show how the international community, especially powerful donors, have highly prioritized AIDS through analyzing data on ODA. Then, I shift perspective to the location of intervention and draw on public opinion data from more than 30 African countries and original survey data from rural Malawi. These data confirm that citizens give relatively weak priority to AIDS interventions, especially when compared to other pressing concerns.

The global mobilization against AIDS in Africa depends on the decisions of local agents implementing interventions on the ground. In Chapter 6, I describe one such agent - village headmen - and detail their priorities and the context in which they make decisions. Because many of Malawi's rural villages lack public services or infrastructure, the headman plays an important role in shaping organization and mobilization to meet the village's needs. My qualitative research shows village headmen engage in a variety of HIV/AIDS interventions. For example, they mediate marital disputes arising from the threat of infecting spouses, they help promote HIV testing to their villagers, and they assist donor organizations in identifying beneficiaries for AIDS orphan programs. In Chapter 6, I provide additional evidence of priority misalignment in the global hierarchy of AIDS intervention in Africa: while headmen's policy priorities are aligned with those of their villagers, their priorities are not aligned with international donors and activists supporting AIDS interventions. Qualitative data demonstrate that when headmen must navigate the competing 
preferences of external donors and local citizens, they favor outcomes beneficial to local people.

In the concluding chapter, I discuss the major findings of the book as well as the implications, not just for interventions against AIDS in Africa, but more generally for interventions to improve the human condition. I conclude the book by raising normative questions about whose priorities should take precedence in democratizing countries in East and Southern Africa, where AIDS has hit hardest. 